\title{
A WebGIS to Support GPR 3D Data Acquisition: A First Step for the Integration of Underground Utility Networks in 3D City Models
}

\author{
P. G. Tabarro ${ }^{\text {a }}$, J. Pouliot ${ }^{\text {a }}$, R. Fortier ${ }^{\text {b }}$, L.-M. Losier $^{\mathrm{c}}$ \\ ${ }^{\text {a }}$ Department of Geomatics Sciences, Université Laval, Québec, Canada - paulo.tabarro.1@ulaval.ca and \\ jacynthe.pouliot@scg@ulaval.ca \\ ${ }^{\mathrm{b}}$ Department of Geology and Geological Engineering, Université Laval, Québec, Canada - richard.fortier@ggl.ulaval.ca \\ ${ }^{\mathrm{c}}$ Geovoxel Inc., Boulevard Charest Est, Québec, Canada - louis.losier@geovoxel.com
}

\section{Commission VI, WG VI/4}

KEY WORDS: GIS, Underground Utility Networks, Ground Penetrating Radar, Subsurface Utility Engineering, 3D Data Acquisition

\begin{abstract}
:
For the planning and sustainable development of large cities, it is critical to accurately locate and map, in 3D, existing underground utility networks (UUN) such as pipelines, cables, ducts, and channels. An emerging non-invasive instrument for collecting underground data such as UUN is the ground-penetrating radar (GPR). Although its capabilities, handling GPR and extracting relevant information from its data are not trivial tasks. For instance, both GPR and its complimentary software stack provide very few capabilities to co-visualize GPR collected data and other sources of spatial data such as orthophotography, DEM or road maps. Furthermore, the GPR interface lacks functionalities for adding annotation, editing geometric objects or querying attributes. A new approach to support GPR survey is proposed in this paper. This approach is based on the integration of multiple sources of geospatial datasets and the use of a Web-GIS system and relevant functionalities adapted to interoperable GPR data acquisition. The Web-GIS is developed as an improved module in an existing platform called GVX. The GVX-GPR module provides an interactive visualization of multiple layers of structured spatial data, including GPR profiles. This module offers new features when compared to traditional GPR surveys such as geo-annotated points of interest for identifying spatial clues in the GPR profiles, integration of city contextual data, high definition drone and satellite pictures, as-built, and more. The paper explains the engineering approach used to design and develop the Web GIS and tests for this survey approach, mapping and recording UUN as part of 3D city model.
\end{abstract}

\section{INTRODUCTION}

\subsection{The lack of Underground Utility Data}

In highly populated areas, a complex mesh of vital utilities such as gas pipelines, power and communication cables, drinking water, and wastewater systems, is buried underground, beyond sight (Figure 1). With the population growth and urban development, it is challenging not only to maintain an up-todate spatial database of existing underground utility networks (UUN) but also to acquire spatial data of buried infrastructures in non-invasive ways (Jeong et al., 2004; Navigant Consulting, 2005; Pouliot and Girard 2016). For any development project requiring excavation and trenching, it has become more and more essential to acknowledge the necessity of having an available and reliable current database of UUN in order to avoid interruption of services and downtime costs due to damage (Costello et al., 2007; Lew and Anspach, 2000; Metje et al., 2007). For example, Info-excavation reported 4.5 damages per day in 2015 for an approximate cost of \$109 million CAN (Info-excavation, 2015).

Ideally, UUN information should be made available to users such as city planners and construction companies to design new city development and avoid service disruption during excavation. In reality, when this database exists, it is not compliant with well-known accepted standards for processing spatial data, such as CityGML Utility Network ADE, INSPIRE network model, IFC utility model, and ESRI ArcGIS network model, leading to an inadequate representation of these structures (Becker, et al, 2012). Only a few places around the world as Switzerland, Norway, the United States of America, India, Malaysia, and some others have shown enough interest in developing structured 3D data of their UUN (Cornette and Galley, 2011; Choon and Seng, 2013; Ghawana et al., 2013; Valstad, 2006).

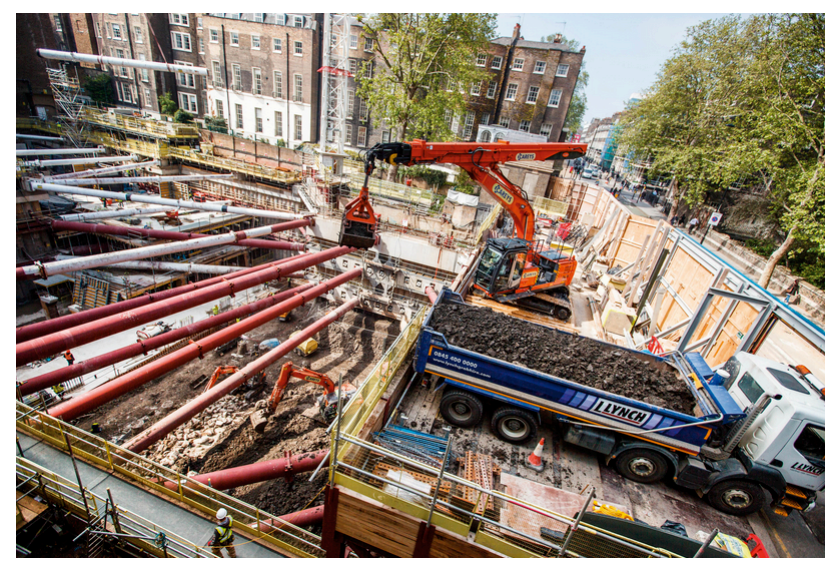

Figure 1. Example of underground utility networks, central London. Image courtesy of Hitachi (source Bentley Intelligent 3D Models). 


\subsection{D Data acquisition with Ground Penetrating Radar}

Among the most accepted non-invasive underground 3D acquisition methods, the Ground Penetrating Radar (GPR) stands up from many others for its capability of covering large areas in a fast and continuous way (Daniels, 2004). Figure 2 shows an example of a GSSI GPR (http://www.geophysical.com/) used to survey UUN's by Geovoxel in the city of Rio de Janeiro, Brazil, before excavating a rail trench. The GPR uses electromagnetic radar signal propagating into the ground to identify the location and the depth of subsurface utilities.

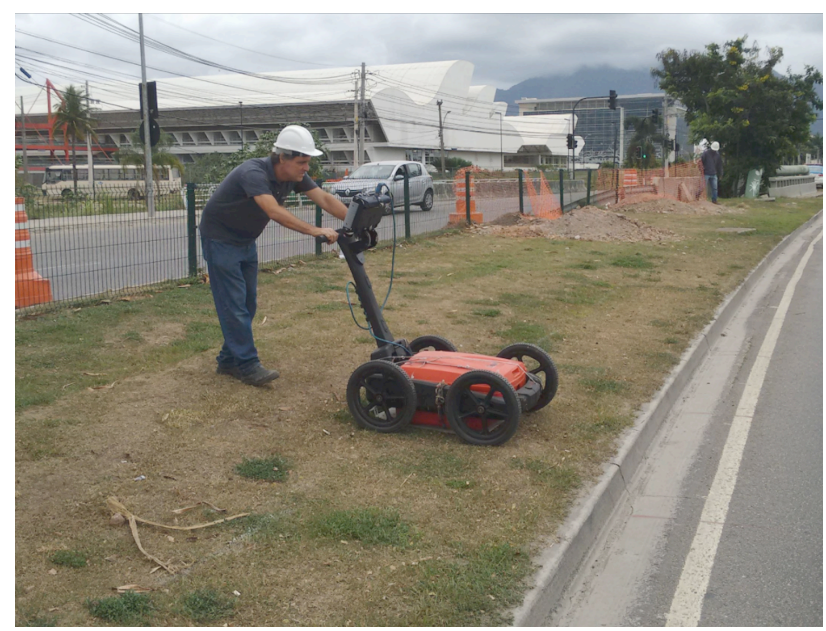

Figure 2. Ground-penetrating radar survey in progress (image courtesy of Geovoxel).

Although GPR has many supporters, its handling is not trivial, even for experts (Annan, 2009; Jol 2008; Rahman and Zayed, 2016). First, it is noticeable that there is a lack of specialized tools to help the data acquisition pipeline, from getting contextual data prepared before going in the field to the visualization of GPR data within the project's context (Dallaire and Garneau, 2008; Pouliot et al., 2016; Li et al., 2015; Themistocleousa, et al., 2015; Talmaki et al., 2013; Tischeler 2003; Zheng et al., 2004). These steps require an integration of resources which varies in format, data organisation, and semantic details. Among the non-specialized tools found in the literature, it counts even less the ones that provide offline support, such as ESRI ArcGIS, for remote areas in which the data acquisition is often performed (Sandweiss et al., 2017; Proulx-McInnis et al., 2013). Subsequently, during the data acquisition, as shown in Figure 3, most of GPR embedded software integrates a real-time display and in-site interpretation tools as signal data processing, but the geographic interaction level remains limited, if simply inexistent. Scarcely any GPR producer has a fast-moving reaction to these technological needs except a few like the EKKO_Project (Sensors \& Software, 2017).

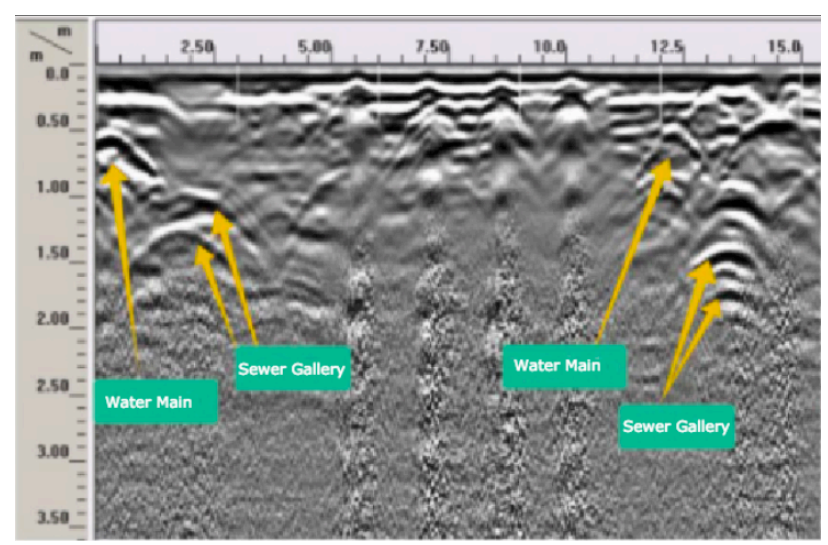

Figure 3. GPR's outcome profile, where $x$ is the length of a surveyed line and y the depth under the ground, in meters, showing hyperbolic diffractions indicating possible UUN's (image courtesy of Geovoxel).

\subsection{Research project objectives}

To conduct a more precise and reliable GPR data survey, it is hypothesized that basic features such as adding annotations, viewing photos, querying attributes or metadata, and drawing while being on-site would be of great benefit to the GPR operators. Furthermore, offering a more comprehensive approach for covering preprocessing, acquisition, and visualization of relevant existing data for on-site consultation contributes to the effectiveness of identifying underground elements in the field. Many manuals and standards provide guideline for collection and mapping of underground infrastructure (ASCE, 2002; CCGA, 2014; Chen and Cohn, 2010; CSA, 2016; Metje et al., 2007). However, these standards do not seem to be known (or sometimes disregarded) by many GPR practitioners.

Based on previous experiments (Pouliot et al., 2016), interview with GPR users, and the literature review, multiple layers' visualization of existing data in parallel to real-time acquired GPR data is perceived as valuable to facilitate the identification of UUN. The main objective of the project, started as of fall 2017, is to demonstrate the value of adding to GPR surveys, GIS capabilities and geo-standards as proposed by OGC (Open Geospatial Consortium). To achieve this, a new approach based on the integration of geospatial city-relevant (i.e. CityGML objects) datasets, the use of a Web GIS and its components is proposed. The project follows an engineering approach as problems with the GPR users were initially identified, a literature review was performed to review the current GPR survey solutions, specific requirements were identified, and, finally, a prototype solution was designed and tested. The tests are based on GPR data of UUN and survey procedures undertaken by Geovoxel during a commercial project executed in the region of Rio de Janeiro.

\section{GVX-GPR - AN INTEGRATED APPROACH}

\subsection{The GIS system - GVX GPR module}

To support GPR deployment in the field and to increase effectiveness and quality of 3D data collection of UUN, Web and GIS capabilities are proposed on portable devices via a Platform-as-a-Service tool called GVX; a marketplace for WebGIS, designed by Geovoxel (http://geovoxel.com/). Geovoxel, a Canadian company focused on geospatial data 
integration, alongside the research team, has noticed the importance and potential to propose UUN integration to Geovoxel's WebGIS marketplace, aiming the improvement of GPR 3D data acquisition time and quality, by assisting this 3D data pipeline.

The GVX, Geovoxel's platform as a service, integrates spatial data collected by remote sensors such as geotechnical instruments for mitigating, on-the-fly, the hazards such as landslides, water floods, dam cracks, and infrastructure collapsing. The GVX also has an innovative dashboard (Figure 4) to support the decision-making process, being a multifunctional GIS which integrates multiple specialized modules in different areas of civil/construction.

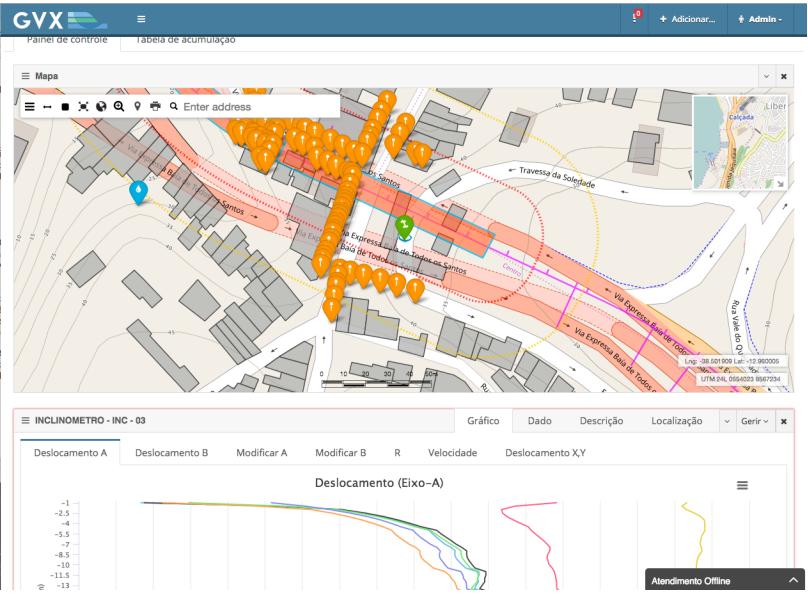

Figure 4. Current GVX's dashboard (image courtesy of Geovoxel).

While Geovoxel has the expertise to manage GPR data, the GVX still needs to provide means for the identification and integration of UUN. The GVX-GPR module supports GPR operators in:

- Conducting a more thorough GPR investigation;

- Increasing efficiency of post processing by reducing uncertainties of collected data;

- Performing smoother and faster production of integrated and versatile maps of GPR investigation to support decision making process for field survey as well as industry-fashioned documentation;

- Proposing more reliable underground infrastructure 3D models, available to a larger community of users.

\subsection{Preliminary Results}

The results and the contributions of this new approach can be presented into two categories. Firstly, the GVX-GPR module is designed and implemented iteratively. Subsequently, a commercial project carried out in Rio de Janeiro - Brazil by Geovoxel is used as a case study to assess the usefulness and the easiness of the interface components, as well as the benefits of such GPR-Web GIS.

\subsubsection{Design of the GVX-GPR module}

Regarding design, Figure 5 shows the overall use case settled for the GPR operators. It proposes capabilities to handle GPR data, integrate project-relevant spatial data, visualize, and export data. Figure 6 presents a class diagram designed to structure and store the spatial data. The data model has its basis found in the CityGML NetworkUtility ADE model (Becker, T. et al, 2012) detracted by the topological component due to the territorial scope of a GPR survey. The potential addition of topology is a current point of assessment by the research team, but it would require different survey techniques to be executed within the same project in order to increase completeness and extent of the surveyed data.

With the capability of drawing points, lines, and polygons on a map interface, users are able to create and represent underground infrastructures by georeferencing them as a result of a 3D GPR data. The interpretation is also handled with the help of map layers, by correlating overlapping data sources in the platform. Likewise, the level of interaction of users with infrastructures allow them to manage metadata such as depth and infrastructure class as proposed by OGC.

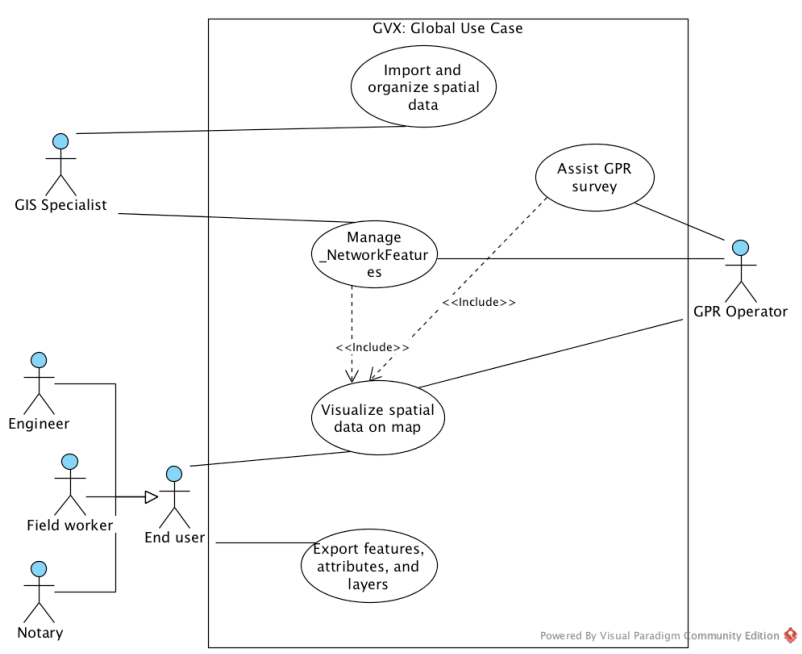

Figure 5. Usecase of the GVX-GPR module.

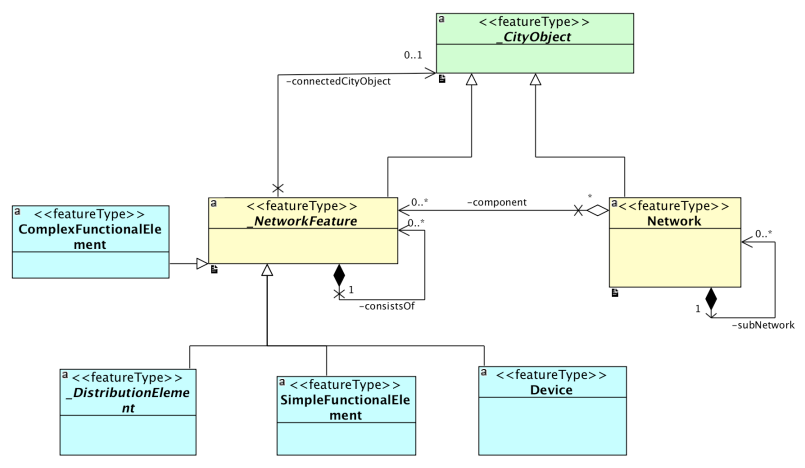

Figure 6. GVX-GPR's class diagram as proposed by OGC.

The next figures illustrate examples of the new GVX-GPR interface. Figure 7 displays a GVX-GPR's mock-up available on portable device as tablet, allowing the overlapping of exist spatial data as road, footprint of buildings, and UUN. Even though the collected data has $3 \mathrm{D}$ information as $\mathrm{Z}$ coordinates or depth, the interface is preliminarily $2 \mathrm{D}$, based on experiments (Pouliot et al., 2016) and constraints imposed by GVX, which currently offers a two-dimensional interface. Furthermore, map and vertical profiles (or cross-sections) were acknowledged more convenient to interact for the target audience. 


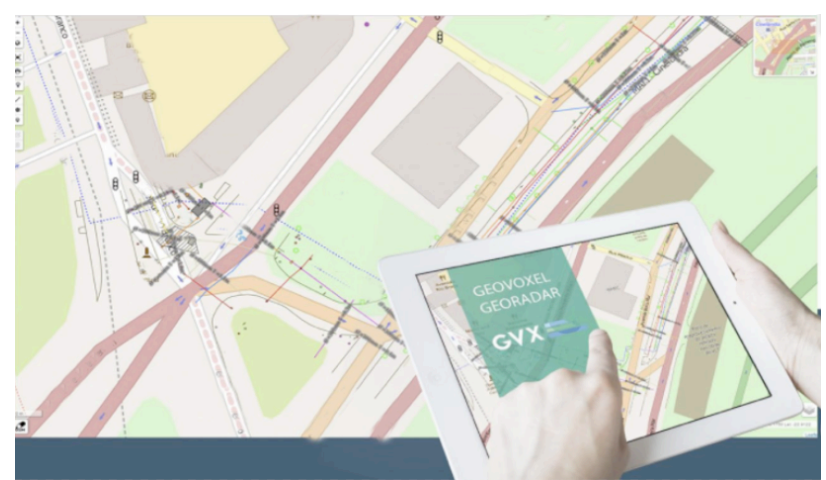

Figure 7. GVX-GPR mock-up interface.

\subsubsection{Case study}

During a first phase of testing, the research team aimed to assess the feasibility of using the approach operated with the new Web GIS module during a GPR survey. The tests also allow us to verify if the sources of spatial data would be relevant to use on field and which were the benefits of mixing GIS features with the geophysical method. The tests were performed within a commercial project by Geovoxel in the region of Rio de Janeiro, for an area of approximately $2600 \mathrm{~m} 2$ wide (Figure 9). The project consisted of discovering unmapped underground infrastructure, objects, tunnels, and galleries.

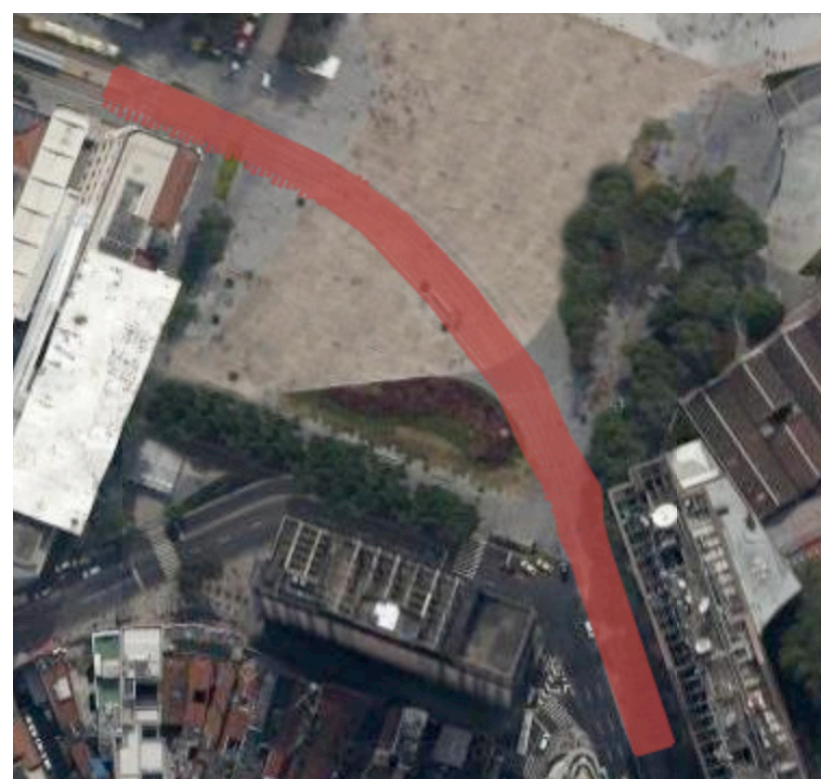

Figure 9. Targeted area (Red polygon) for the GPR survey.

Before the survey begin, the GPR specialists were accompanied in the planning stage, when the area to be surveyed was divided into smaller blocks to facilitate its management and execution. At first, the specialists took note of the covered blocks by selecting four pairs of coordinates for each, and creating an equally spaced mesh, $2 \mathrm{~m} \times 1 \mathrm{~m}$, as shown in Figure 10. Each of the composing lines of this mesh generated a linear profile picture revealing the interferences in the soil. Figure 10 shows the mesh, represented by the red lines, as well as a selected survey line, highlighted in white, and its resulting image. During the acquisition, a member of the research team fed the data collected by Geovoxel's GPR into GVX-GPR.
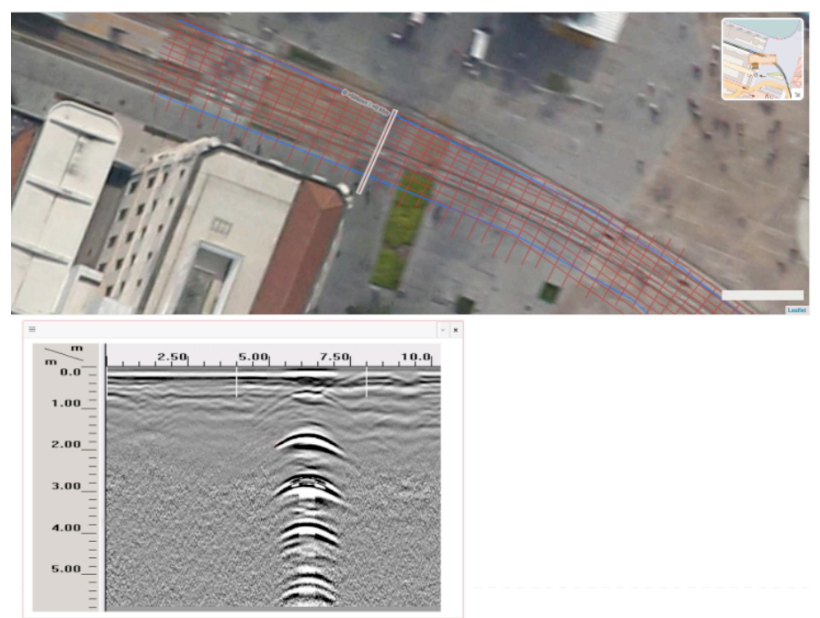

Figure 10. A georeferenced GPR profile indicating a water main's existence with approx. $50 \mathrm{~cm}$ of diameter, $65 \mathrm{~cm}$ deep in the ground. The red lines, representing the mesh, and blue lines, already identified infrastructures.

Once the survey ended, the data, already integrated into the system, was presented to end users, including engineers, managers, and directors, and a land surveyor, as an initial attempt to measure general approval. According to this first test and users' feedback, during the interpretation of such objects, having the ability to interact with GPR data, even in its semiraw format, facilitated the comprehension and 'spatial notion' of the studied area's location for both specialists and nonspecialists. As it is possible to be noticed in figure 11, the high density of UUN's and city objects makes it likely for GPR professionals to misinterpret already-sampled locations.

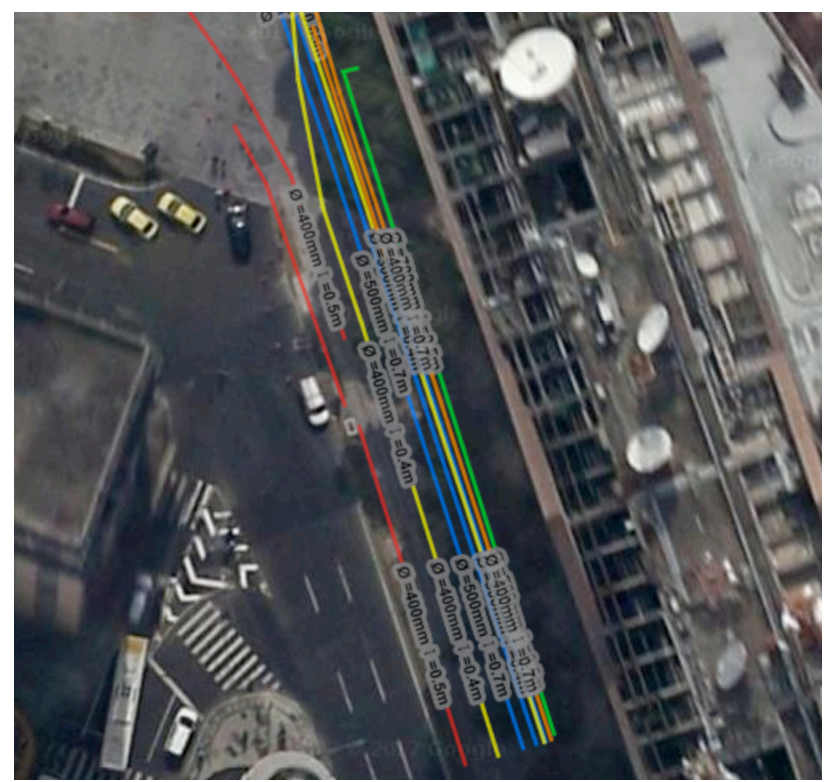

Figure 11. An example of an agglomeration of buried infrastructures in the same avenue discovered by the GPR survey.

It has been observed that the ability of associating complex underground imaging with a map and its elements, such as manholes and poles, contributes for the likelihood of finding objects in the surveyed area. Also, current methods for 
extracting data of the project's surroundings and maintaining them as a last-longing structured data sources can be significantly improved with a specialized tool. Moreover, GPR data starts to play a role of an integrating data that will be kept as a record of the history of events which took place over the years, helping the resolution of future damage.

\section{CONCLUSION}

This project proposes a new approach based on a Web GIS to increase efficiency and user experience during GPR surveys. As far as we know, it is the first attempt made in this direction. The new approach, based on the integration of multiple sources of spatial data and exploiting Web and GIS capabilities on a portable device coupled to GPR instruments (software) show notable improvements to conducting GPR surveys. First, it significantly increases the completeness of surveys and allows the users to store a greater number of structured data. These features increased the efficiency of data post-processing and enlarge data reliability. Furthermore, applying a standardised data modeling when performing GPR data acquisition and management, allowed us to demonstrate the importance of having integrated underground networks in a $3 \mathrm{D}$ city model environment.

While in the past the data analysis was done with the aid of CAD plants and blueprints, the level of interaction that users have when doing the survey process with map other types of geo-annotated media brings up the benefits of linking domains that were apart for too long. According to users' feedback, the module helps not only to store this data in organized manner but also helps specialists and non-specialists to locate infrastructures that, before, required expertise in the domains such as civil engineering and geophysics. Moreover, the capability of assessing possible conflicts of underground networks, during planning and execution, diminishes costs in redesigning the project.

For the next steps, the module will be undertaken in a series of field experiments that aim to validate its use before and during a GPR survey. For instance, a quantitative evaluation on how the time spent performing a survey is be affected as well as the data quality being extracted from the analysis will be performed. Once these outcomes are achieved, features such as adding data of different natures (3D raw cubes, pre-processed data) will be added and validated with users with the view of expediting high quality GPR surveys with less complexity for new likely users.

\section{ACKNOWLEDGEMENTS}

We would like to thank MITACS (a national, not-for-profit, organization dedicated to supporting applied and industrial research in mathematical sciences and associated disciplines in Canada) and Geovoxel to financially support this research project.

\section{REFERENCES}

ASCE, 2002. Standard Guideline for the Collection and Depiction of Existing Subsurface Utility Data (38-02). ASCE report C-I 38-02, New York.

Annan, A. P., 2009. Electromagnetic Principles of Ground Penetrating Radar.

Becker, T., Nagel, C., Kolbe, T. H., 2013. Semantic 3D Modeling of Multi-Utility Networks in Cities for Analysis and
3D Visualization. In: J. Pouliot, S. Daniel, F. Hubert, \& A. Zamyadi (Eds.), Progress and New Trends in $3 D$ Geoinformation Sciences. Berlin, Heidelberg: Springer Berlin Heidelberg, pp. 225-234.

Benedetto, A., and Pajewski, L., 2015. Civil engineering applications of ground penetrating radar. Springer Transactions in Civil and Environmental Engineering.

CCGA, 2014. Underground Infrastructure Damage Prevention, Best Practices V1.0, Report of Canadian Common Ground Alliance (CCGA).

Chen, H., and Cohn, A. G., 2010. Buried Utility Pipeline Mapping Based on Street Survey and Ground Penetrating Radar. Proc. of European Conference on Artificial Intelligence (ECAI 2010), Lisbon, Portugal. (16-20 Aug 2010).

Choon, T. L., and Seng, L. K., 2013. Towards Malaysian Multipurpose 3D Cadastre base on Land Administration Domain Model (LADM)-An Empirical Study.

Cornette, G., and Galley, V., 2011. Géoréférencement des réseaux enterrés: des techniques de relevé à la gestion. XYZ(127), 24-28.

Costello, S. B., Chapman, D. N., Rogers, C. D. F., Metje, N., 2007. Underground Asset Location and Condition Assessment Technologies. Journal of Tunnelling and Underground Space Technology, Vol. 22, pp. 524-542.

CSA (Canadian Standards Association), 2016. CAN/CSAZ247-15 National Standard of Canada: Damage prevention for the protection of underground infrastructure: CSA Group.

Daniels, D. J., 2004. Ground Penetrating Radar (2nd ed.): The Institution of Electrical Engineers, London, United Kingdom.

Dallaire, P. L., and Garneau, M., 2008. The use of a groundpenetrating radar (GPR) to characterize peat stratigraphy and estimate the carbon pool in a boreal peatland, Eastmain region, James Bay, Québec, Canada, 12th International Conference on Ground Penetrating Radar. Birmingham, UK. (16-19 Jun. 1999).

Ghawana, T., Hespanha, J., Khandelwal, P., Van Oosterom, P., 2013. 3D cadastral complexities in dense urban areas of developing countries: case studies from Delhi and satellite towns. Paper presented at the FIG Working Week 2013 in Nigeria-Environment for Sustainability, Abuja, Nigeria. (6-10 May 2013).

Info-excavation, 2015. Outil de rapport sur les dommages aux infrastructures (ORDI). Retrieved from http://www.infoex.com/wp-content/uploads/2013/11/Rapport-ordi-2015finalbasse_resolution.pdf.

Jeong, H. S., Abraham, D. M., Lew, J. J., 2004. Evaluation of an emerging market in subsurface utility engineering. Journal of construction engineering and management, 130(2), pp. 225-234.

Jol, H., 2008. Ground Penetrating Radar Theory and Applications: Elsevier Science.

Lew, J. J., and Anspach, J. H., 2000. Elimination of Utility Line Cuts on a highway Project Using Subsurface Utility Engineer. Proceedings CIB W99, Int. Conf. on Designing for Safety and Health, London. (26-27 Jun. 2000). 
Li, S., Cai, H., Kamat, V. R., 2015. Uncertainty-Aware Geospatial System for Mapping and Visualizing Underground Utilities. Automation in Construction, Volume 53, May 2015, pp. 105-119.

Metje, N., Atkins, P. R., Brennan, M. J., Chapman, D. N., Limb, H. M., Machell, J., Muggleton, J. M., Pennock, S., Ratcliffe, J., Redfern, M., Rogers, C. D. F., Saul, A. J., Shan, Q., Swingler, S., Thomas, A. M., 2007. Mapping the Underworld - State-ofthe-art Review. Journal of Tunnelling and Underground Space Technology, Vol. 22, No. 5-6, pp. 568-586.

Navigant Consulting, 2005. A Review of Electric Utility Undergrounding Policies and Practices. Report prepared for Long Island Power Authority. March 8.

Pouliot, J., and Girard, P., 2016. Subsurface Utility Network Registration and the Publication of Real Rights: Towards Full 3D Cadastre. FIG Working week, Christchurch, NZ. (2-6 May 2016).

Pouliot, J., Lavoie, J-M, Fortier, R., Fortin, J., Auger, R., Naud, A., 2016. Expérimentations d'un géoradar (GPR) pour des levés d'arpentage et de cartographie d'un site archéologique et de réseaux souterrains. Géomatique 2016 ACSG. Montréal, Canada. (19-20 Oct. 2016).

Proulx-McInnis, S., St-Hilaire, A., Rousseau, A. N., Jutras, S., 2013. A review of ground-penetrating radar studies related to peatland stratigraphy with a case study on the determination of peat thickness in a northern boreal fen in Quebec, Canada. Progress in Physical Geography, 37(6), pp. 767-786. doi: $10.1177 / 0309133313501106$

Rahman, M. A., and Zayed, T., 2016. Developing Corrosion Maps of RC bridge elements based on automated visual image analysis. Conference of the Transportation Association of Canada, Toronto, ON. (25-28 Sep. 2016).

Sandweiss, D. H., Kelley, A. R., Belknap, D. F., Kelley, J. T., Rademaker, K., Reid, D. A., 2017. GPR identification of an early monument at los Morteros in the Peruvian coastal desert. Quaternary Research, 73(3), pp. 439-448. doi:10.1016/j.yqres.2010.03.002

Sensors \& Software, 2017. EKKO_Project ${ }^{\mathrm{TM}}$ Software. Retrieved from https://www.sensoft.ca/products/ekkoproject/overview/

Talmaki, S., Kamat, V.R., Cai, H., 2013. Geometric Modeling of Geospatial Data for Visualization-Assisted Excavation. Advanced Engineering Informatics, Elsevier, Vol. 27 (2), p. 283-298.

Themistocleousa, K., Agapioua, A., Papachristodouloua, A., Evlogimenosa, P., Theodoroua, M., Sotiropoulosb, P., Hadjimitsisa, D.G., 2015. Geo-radar Scanning and GIS mapping of an Old Water Utility Network in Paphos District Area in Cyprus Under the Project: 'Upgrade of the hydraulics laboratory for the modeling of water supply networks \& design and operation optimization study'. First International Conference on Remote Sensing and Geoinformation of the Environment, Paphos-Cyprus. (8-10 Apr. 2015).

Tischler, M. A., 2003. Integrating Ground-Penetrating Radar, Geographic Information Systems and Global Positioning Systems for 3-Dimensional Soil Modeling. Thesis Presented to the Graduate School of the University of Florida, Degree of Master of Science.

Valstad, T., 2006. Developments of the 3D Cadastre in Norway. XXIII FIG Congress, Munich, Germany. (8-13 Oct. 2006).

Zheng, C.B., Qi, H.Q., Dong, L.W., 2004. The Utilization of GPR Data in GIS. Geoinformatics, Proc. 12th Int. Conf. on Geoinformatics - Geospatial Information Research: Bridging the Pacific and Atlantic, University of Gävle, Sweden. (7-9 Jun. 2004). 